\title{
Klaus Oschema, Bilder von Europa im Mittelalter
}

Ostfildern : Thorbecke (Mittelalter-Forschungen, 43), 2013, 678 p., 85,00€

Pierre Monnet

\section{OpenEdition}

\section{Journals}

Édition électronique

URL : http://journals.openedition.org/ifha/8139

DOI : 10.4000/ifha.8139

ISSN : 2198-8943

Éditeur

IFRA - Institut franco-allemand (sciences historiques et sociales)

Référence électronique

Pierre Monnet, "Klaus Oschema, Bilder von Europa im Mittelalter », Revue de l'IFHA [En ligne], Date de recension, mis en ligne le 14 avril 2015, consulté le 22 septembre 2020. URL : http://

journals.openedition.org/ifha/8139; DOI : https://doi.org/10.4000/ifha.8139

Ce document a été généré automatiquement le 22 septembre 2020

CIFHA 


\section{Klaus Oschema, Bilder von Europa im Mittelalter}

Ostfildern : Thorbecke (Mittelalter-Forschungen, 43), 2013, 678 p., 85,00€

\section{Pierre Monnet}

Depuis que l'histoire globale s'est emparée de la corporation des historiens, la provincialisation de l'Europe, le décentrement, la dénonciation de l'européocentrisme font légitimement florès, au point que parler d'Europe ou d'histoire européenne devient au mieux un peu désuet, au pire quelque peu suspect. Qu'il faille extraire le regard du cadre européen pour comparer, pour observer les connexions, les transferts, les croisements, ne fait guère de doute. Mais de quelle Europe «s'affranchir ", telle est là aussi la question. Le livre de Klaus Oschema n'entend pas, au terme de plus de 670 pages, délivrer une réponse toute faite à cette interrogation. Il y est bien question d'Europe mais ce serait mal lire l'ouvrage et mal connaître son auteur que de penser que l'on y trouvera une définition toute faite utile aux politiques ou aux acteurs culturels de notre temps. Le Moyen Âge a bien entendu connu le mot «Europe », sinon cette étude n'existerait pas, et l'époque s'en est forgée des représentations, des images, des discours, des métaphores, mais dans un contexte si varié, si différent, que la rétroprojection ou l'instrumentalisation d'une prétendue idée de l'Europe médiévale à des fins contemporaines renvoie immanquablement aux présupposés, à l'inconscient, aux finalités politiques, pour le coup souvent suspectes, de leurs auteurs. Telle est la belle, telle est la grande leçon du livre.

Celui-ci se divise en deux temps. Les onze premiers chapitres progressent par grands mouvements chronologiques, depuis un héritage antique mêlant mythologie, catégorisation géographique, linguistique et ethnique, dans une profusion et une indétermination que non seulement le Moyen Âge ne renie pas mais transforme en machine à savoir, à penser et à se projeter : pas plus, mais pas moins non plus. Les six derniers chapitres procèdent davantage par approche thématique en jouant sur les images et fonctions de la représentation : tantôt classement des parties et des cultures du monde, tantôt réservoir de mythes, d'origines, de symboles, tantôt vision ou simple état descriptif des choses. Le mot «Europe", pas si rare que cela tout compte fait, a 
quand même eu pour fonction de mettre de l'ordre, de faire fonctionner une représentation du monde, mais très loin des prétendues supériorités et homogénéités que notre contemporanéité prétend vouloir y placer. Le terme ou son image n'évoquent en rien dans les siècles médiévaux un destin, une construction politique, une entité bonne en soi et supérieure aux autres. Tout au plus le $\mathrm{xv}^{\mathrm{e}}$ siècle voit, avec l'émergence de la puissance ottomane et de son expansion en Europe continentale (une obsession, que l'on ne saurait cependant confondre avec une crainte de l'Islam), se diffuser un discours de défense de l'Europe non parce qu'elle serait en soi « européenne » mais en qualité de siège de Rome et de son Église. Mais en dehors de cette lente montée d'un paroxysme obsidional, l'Europe des Médiévaux n'est pas ce mot-valise prospectif ou ce dépôt d'idéologie auquel puiseraient tous les conquérants des nouveaux mondes : c'est même plutôt une représentation assez modeste, de toute façon située en concurrence avec d'autres principes bien plus forts et surtout par essence universels et œcuméniques (la foi catholique, la papauté, l'idée d'Empire...), à tout prendre pas encore européo-centrée ainsi qu'elle le deviendra plus tard. Comme c'est d'ailleurs le cas pour le terme de nation, il faut donc se débarrasser de couches ultérieures et téléologiques (Charlemagne père de l'Europe, les croisades comme un combat européen, l'opposition chrétienté versus islam) pour retrouver une fonction cognitive du terme au cœur du Moyen Âge, qui a connu l'idée d'Europe sans que celle-ci soit arrimée à la notion d'un « homo europeus ». Dès lors, ce sont les logiques argumentatives contemporaines détournant l'idée européenne médiévale à leur profit qui nous en disent bien davantage sur la culture et les contradictions politiques et culturelles de notre temps. Et, pour se rassurer une toute dernière fois, il suffit de relire les pages conclusives du magnifique livre de Klaus Oschema pour se convaincre que, vue de l'extérieur, cette Europe des siècles médiévaux n'était pas davantage pourvue de l'identité et de la force que les nostalgiques souhaiteraient y trouver: les Musulmans parlent plus volontiers des siècles durant des « Romains » ou des « Francs », sans même évoquer la Chine déjà impériale et qui se concevait alors, sans avoir besoin du biais européen, comme le centre du monde. Il faudra alors pour imposer aux autres l'idée européenne, bien des conquêtes et bien des dominations, qui ne sont pas du Moyen Âge, et qui ne sont sûrement pas la meilleure des leçons que l'Europe a pu proposer au reste du monde. Mais c'est là une autre histoire.

\section{INDEX}

Index chronologique : Moyen Âge

Thèmes : Histoire de la culture, Histoire des mentalités, Histoire des idées

\section{AUTEUR \\ PIERRE MONNET}

EHESS, IFHA 